\title{
Synthesis and characterization of a new photoinduced switchable $\beta$-cyclodextrin dimer
}

\author{
Florian Hamon ${ }^{1}$, Claire Blaszkiewicz ${ }^{1,2}$, Marie Buchotte ${ }^{3}$, Estelle Banaszak-Léonard ${ }^{3}$, \\ Hervé Bricout ${ }^{2}$, Sébastien Tilloy ${ }^{2}$, Eric Monflier ${ }^{2}$, Christine Cézard ${ }^{1}$, Laurent Bouteiller ${ }^{4,5}$, \\ Christophe Len $^{3}$ and Florence Djedaini-Pilard ${ }^{* 1}$
}

\section{Full Research Paper}

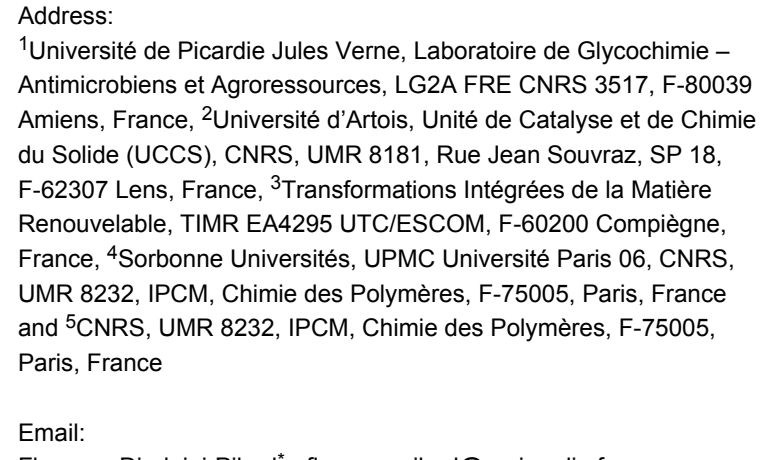

${ }^{1}$ Université de Picardie Jules Verne, Laboratoire de Glycochimie Antimicrobiens et Agroressources, LG2A FRE CNRS 3517, F-80039 Amiens, France, ${ }^{2}$ Université d'Artois, Unité de Catalyse et de Chimie du Solide (UCCS), CNRS, UMR 8181, Rue Jean Souvraz, SP 18 F-62307 Lens, France, ${ }^{3}$ Transformations Intégrées de la Matière Renouvelable, TIMR EA4295 UTC/ESCOM, F-60200 Compiègne, France, ${ }^{4}$ Sorbonne Universités, UPMC Université Paris 06, CNRS, UMR 8232, IPCM, Chimie des Polymères, F-75005, Paris, France and ${ }^{5}$ CNRS, UMR 8232, IPCM, Chimie des Polymères, F-75005, Paris, France

\section{Email:}

Florence Djedaini-Pilard - florence.pilard@u-picardie.fr

* Corresponding author

\section{Keywords:}

azobenzene; cyclodextrins; inclusion complex; photoisomerization; switchable binding behavior

\author{
Beilstein J. Org. Chem. 2014, 10, 2874-2885. \\ doi:10.3762/bjoc. 10.304
}

Received: 10 July 2014

Accepted: 06 November 2014

Published: 04 December 2014

This article is part of the Thematic Series "Superstructures with cyclodextrins: Chemistry and applications II".

Guest Editor: G. Wenz

(C) 2014 Hamon et al; licensee Beilstein-Institut. License and terms: see end of document.

\begin{abstract}
This paper reports an efficient preparation of bridged bis- $\beta$-CD AZO-CDim 1 bearing azobenzene as a linker and exhibiting high solubility in water. The photoisomerization properties were studied by UV-vis and HPLC and supported by ab initio calculations. The cis/trans ratio of AZO-CDim 1 is 7:93 without irradiation and 37:63 after 120 min of irradiation at $365 \mathrm{~nm}$; the reaction is reversible after irradiation at $254 \mathrm{~nm}$. The photoinduced, switchable binding behavior of AZO-CDim 1 was evaluated by ITC, NMR and molecular modeling in the presence of a ditopic adamantyl guest. The results indicate that AZO-CDim 1 can form two different inclusion complexes with an adamantyl dimer depending on its photoinduced isomers. Both cavities of cis-AZO-CDim 1 are complexed simultaneously by two adamantyl units of the guest forming a 1:1 complex while trans-AZO-CDim 1 seems to lead to the formation of supramolecular polymers with an $n: n$ stoichiometry.
\end{abstract}

\section{Introduction}

$\alpha$-, $\beta$ - or $\gamma$-Cyclodextrins (CDs) are cyclic oligosaccharides composed of 6,7 or $8 \alpha$-D-1,4 glucopyranose moieties, respectively. They are natural compounds produced from starch by the reaction of 4- $\alpha$-glucanotransferases [1]. Their toroidal shape, with C6-primary hydroxy groups on the narrow rim and $\mathrm{C} 2$ and C3 secondary groups on the wider rim, enables encapsulation of 
hydrophobic molecules inside their cavity. Since the 1950s, it has been demonstrated that CDs can form non-covalent-force complexes in water due to their unique spatial arrangement. In particular, $\beta$-cyclodextrin $(\beta-C D)$ is known to form supramolecular inclusion complexes with molecules, and such inclusion usually enhances the solubility of water-insoluble substances [1-4]. Pharmaceutical companies already use these cyclodextrins or their derivatives in their formulations $[5,6]$. In fact, they have a well-defined structure, low toxicological or pharmacological activity, and good solubility in water. For example, the inclusion of active substances in CDs can reduce their undesirable storage or metabolism degradation, which has led research on CDs to focus on controlled drug delivery [4]. In the food industry, CDs enable the fixation or retention of volatile flavors, as well as the removal of undesirable flavors from food $[7,8]$.

In comparison with $\mathrm{CD}$ monomers, bridged bis-cyclodextrins can improve the original binding ability of native CDs through the cooperative binding of both cavities located close to the guest molecules $[9,10]$. These cyclodextrins linked by ester [11], thioether [12-16], urea [17-19], or triazole [20] moieties have been previously described. In addition, aromatic azobenzenes are excellent candidates as molecular switch linkers as they have two forms, namely cis $(Z)$ and trans $(E)$ isomers, which can be interconverted by both photochemical and thermal means [21]. This transformation by external stimuli induces a molecular movement and a significant geometric change $[22,23]$. CDs and azobenzene derivatives can form inclusion complexes controlled by photoisomerization of the guests and this property has been widely applied to molecular shuttles, motors, information storage [24,25] and catalysis [26].

Some examples of azobenzene-linked CD dimers can be found in the literature but they generally suffer from arduous purification steps and very low yields $[27,28]$. As an exception, Vargas et al. [29] described the synthesis of 1,2,3-triazole-linked azobenzene-cyclodextrin derivatives producing rather good yields but the photoisomerization and inclusion complex properties were not investigated. Here, we report an efficient preparation of a new bis- $\beta$-CD with azobenzene dicarboxylate and the influence of photoisomerization of the linker on the conformation and binding behavior of the $\mathrm{CD}$ dimer.

\section{Results and Discussion}

The AZO-CDim 1 synthesis was performed as follows: 4,4'azobenzenedicarboxylic acid was first obtained by reductive coupling of 4-nitrobenzoic acid with a yield of $49 \%$ (Scheme 1) [30]. Then, the carboxylic groups were activated by $N$-hydroxysuccinimide (NHS) and condensed with mono-6-amino-6-

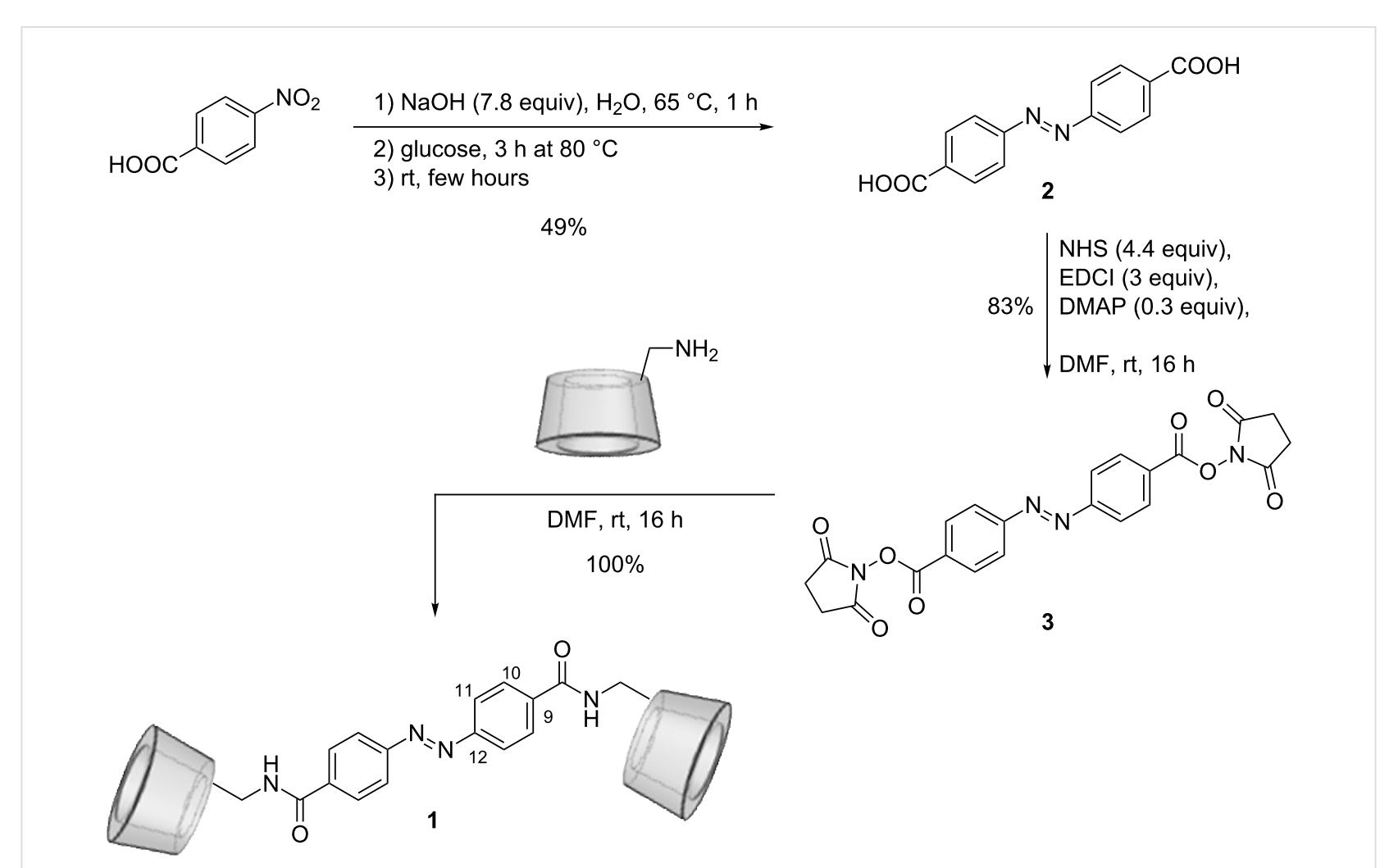


deoxy- $\beta$-cyclodextrin $\left(\beta-\mathrm{CD}-\mathrm{NH}_{2}\right)[31]$ in anhydrous DMF at room temperature. Flash chromatography $\left(\mathrm{C}_{18}\right.$ column, $\mathrm{H}_{2} \mathrm{O}$ / $\mathrm{MeOH}$ 90:10 to 10:90 v/v in $20 \mathrm{~min}$ ) afforded pure AZO-CDim 1 with $62 \%$ yield.

It should be noted that AZO-CDim 1 exhibits surprisingly high solubility in water, reaching $220 \mathrm{mM}$ at $293 \mathrm{~K}$, even though the linker is hydrophobic and the solubility of $\beta-\mathrm{CD}$ is only $16 \mathrm{mM}$ under the same conditions. Concentration-variable NMR analysis revealed a strong upfield shift and a broadening of the proton signals. No significant chemical shift variations were observed at concentrations below $1 \mathrm{mM}$, which is consistent with a critical aggregation concentration of around $1 \cdot 10^{-3} \mathrm{M}$.

The UV-vis absorption spectrum of azobenzene presents three characteristic absorption bands (250, 320 and $450 \mathrm{~nm})$ corresponding to $\pi-\pi^{*}$ and $n-\pi^{*}$ electronic transitions, respectively. For the trans isomer, the absorption band $\pi-\pi^{*}$ at $320 \mathrm{~nm}$ is very intense while the other two bands $\left(\pi-\pi^{*}\right)$ at $250 \mathrm{~nm}$ and $\left(\mathrm{n}-\pi^{*}\right)$ at $420 \mathrm{~nm}$ are much weaker. For the cis isomer, the absorption band $\pi-\pi^{*}$ is shifted slightly to a shorter wavelength and is significantly less intense at $320 \mathrm{~nm}$. Because the $n-\pi^{*}$ transition is possible in the cis isomer, this band increases in intensity [22,23]. A molecular switch is based on the lightinduced, reversible transformation of chemical species between two molecular states with different absorption spectra. Thus, the trans/cis isomerization can be reversibly controlled through UV light irradiation as depicted in Figure 1. As shown in Figure 1a, when a sample containing AZO-CDim $\mathbf{1}$ in pure water at room temperature was UV irradiated at $365 \mathrm{~nm}$, it switched from its trans to its cis form resulting in a marked change in the UV-vis spectra. As the irradiation continued, the absorption band at around $320 \mathrm{~nm}$ gradually decreased while the bands at $420 \mathrm{~nm}$ and $250 \mathrm{~nm}$ slightly increased. This change is clearly due to the simple, but partial, isomerization of the azo groups from the trans photoisomer to the cis photoisomer [21]. The maximum isomerization yield was obtained after $120 \mathrm{~min}$ of irradiation at $365 \mathrm{~nm}$.

The reaction is reversible and when irradiated at $254 \mathrm{~nm}$ (Figure 1b), the cis isomer of AZO-CDim 1 gradually returned to its trans form, and the maximum isomerization yield was obtained after $90 \mathrm{~min}$ of irradiation. Both isomers could be separated by HPLC (Dionex, $\mathrm{H}_{2} \mathrm{O} / \mathrm{MeCN}$ 90:10) and the cis/trans ratio of AZO-CDim 1 before irradiation (7:93) and after $2 \mathrm{~h}$ of irradiation (37:63) at $365 \mathrm{~nm}$ was determined (Figure 2). Although each isomer could not be obtained in pure form, as is often the case for many azoderivatives [32], the isomerization efficiency is better than the cis/trans ratio of 14:86 after irradiation described by Liu [27].

Both isomers of AZO-CDim 1 have an appreciable resistance to fatigue thus the irradiation cycle could be carried out several times without causing side effects, as shown in Figure 3.

$\mathrm{Ab}$ initio calculations were also performed but the cis/trans transition was not observed since molecular modeling methods are unable to break bonds. In order to collect data on this phenomenon, the two configurations of the system had to be taken into account separately. Thus, ab initio calculations were

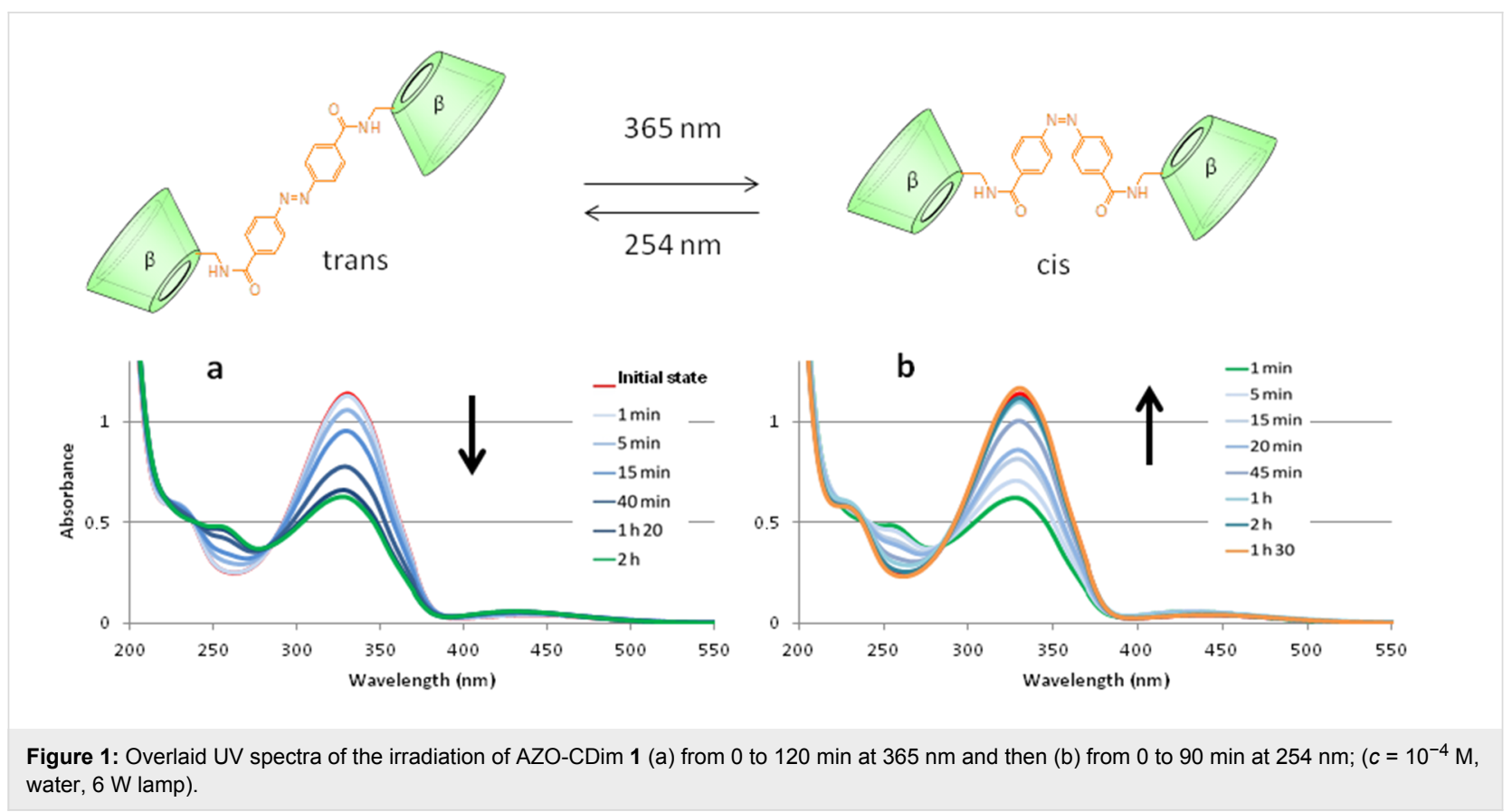



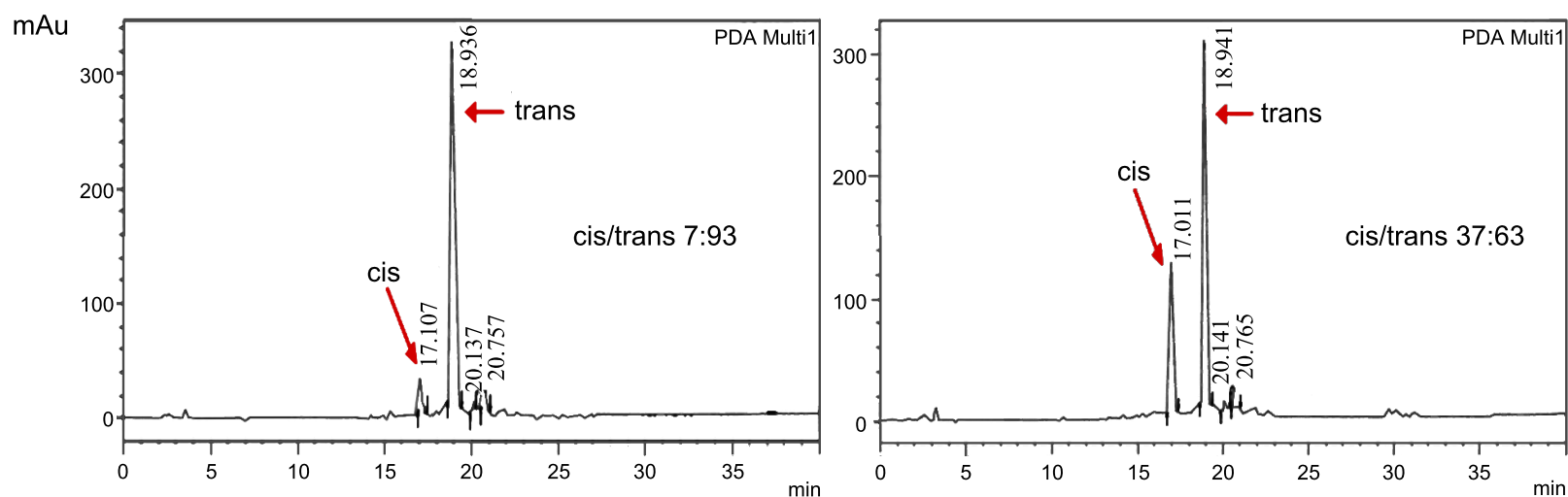

Figure 2: HPLC quantification of the cis/trans ratio of AZO-CDim 1 before irradiation (left) and after irradiation at $365 \mathrm{~nm}(2 \mathrm{~h}, 6 \mathrm{~W}$ lamp) (right).

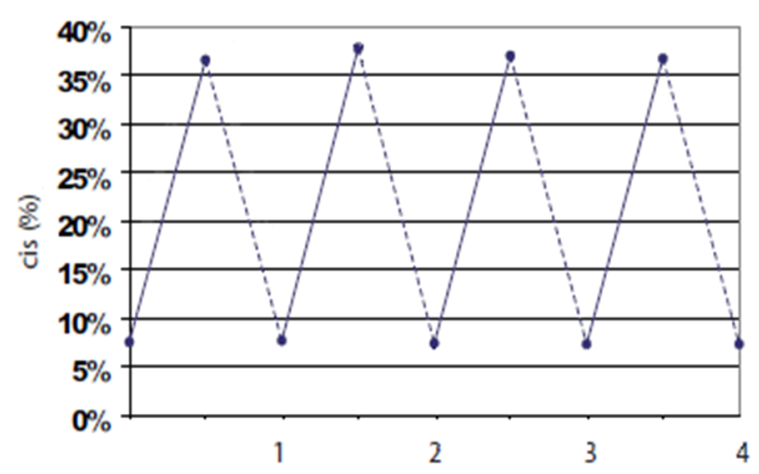

Figure 3: Percentage of cis isomer of AZO-CDim 1 produced during photoisomerization cycles $\left(c=10^{-4} \mathrm{M}\right.$, water). A cycle consists of irradiation at $365 \mathrm{~nm}$ for $2 \mathrm{~h}$ followed by irradiation at $254 \mathrm{~nm}$ for $1 \mathrm{~h}$. performed on the two configurations of the azobenzene linker, the so-called 4,4'-bis( $N$-methylcarboxamide)azobenzene linker, to determine the structures of minimal energy (Figure $4 \mathrm{a}$ and Figure 4b). Once optimized, the measured C4-C4' distances were 9.1 and $6.6 \AA$ for the trans and cis configurations, respectively, and the $\mathrm{C}-\mathrm{N}=\mathrm{N}-\mathrm{C}$ dihedral angles were $180^{\circ}$ and $-10^{\circ}$, respectively. These results are comparable to those obtained by Koshima et al. [33,34] on crystal structures where intermolecular packing effects might be important. From these calculations, the geometrical force field parameters needed for molecular dynamics simulations were derived.

Molecular dynamics simulations performed on the two configurations of AZO-CDim 1 highlighted the rigidity of the linker, which governs the relative position of the two $\mathrm{CD}$ cavities. The<smiles>CC1C(C)C(C(C)C(C)(C)C)C(C)C(C)C1C=NC1C(C)C(C)C(C(C)C(C)(C)C(C)(C)C)C(C)C1C</smiles>

\section{b}<smiles>CC(C)C(C)C(C)C(C)C1C(C)C(C)C(CCC2C(C)C(C)C(C(C)C(C)C(C)C)C(C)C2C)C1C</smiles>

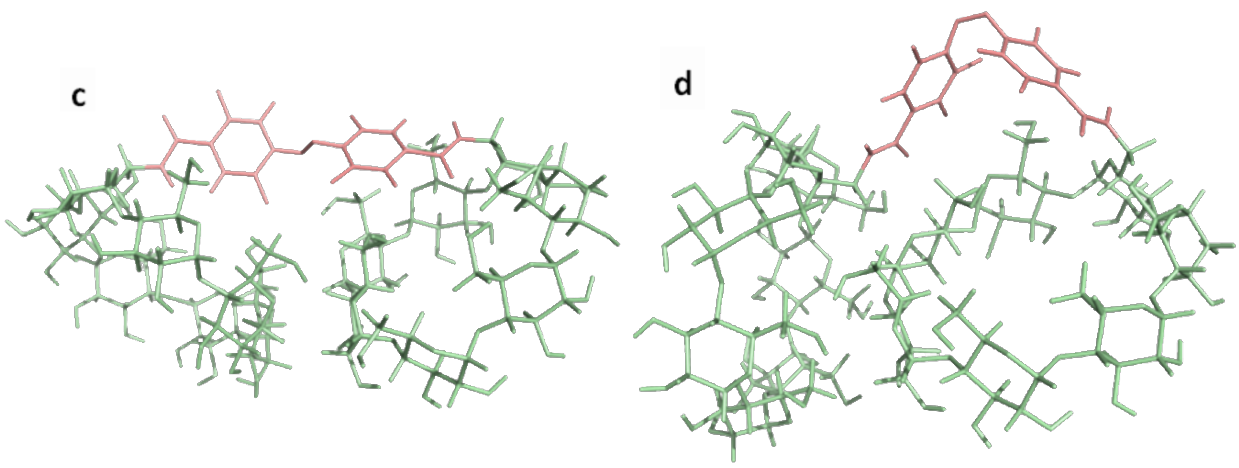

Figure 4: Representation of the most stable structures obtained for the azobenzene linker (a) for the trans configuration and (b) for the cis one and for the AZO-CDim 1 systems (c) for the trans configuration and (d) for the cis one. 
trajectories, corresponding to 50,000 snapshots, were clustered into thirty representative conformations. The most stable structure of these thirty representative conformations for each configuration is shown in Figure 4c and Figure 4d. It should be kept in mind that although the linker is quite rigid, the two $C D$ cavities can rotate and move around the azobenzene axis. Throughout the simulations, the $\mathrm{C} 4-\mathrm{C} 4$ ' distances and the $\mathrm{C}-\mathrm{N}=\mathrm{N}-\mathrm{C}$ dihedral angles did not fluctuate much. The $\mathrm{C}-\mathrm{C}$ average value was $8.9 \pm 0.1$ and $5.8 \pm 0.3 \AA$ and the $\mathrm{C}-\mathrm{N}=\mathrm{N}-\mathrm{C}$ dihedral angle was $175.1 \pm 4.8$ and $-6.3 \pm 5.4^{\circ}$ for the trans and cis configurations, respectively.

In these conditions, using azobenzene as a linker between two $\beta$-CD can lead to a modulation of the inclusion properties, such as a cooperative effect. The cavity of each $\mathrm{CD}$ is available to form an inclusion complex with a hydrophobic guest molecule. Among these, adamantane is known to be an excellent guest for the $\beta$-CD cavity, with an association constant $K_{\mathrm{a}}$ ranging from $2 \cdot 10^{4} \mathrm{M}^{-1}$ to $4 \cdot 10^{4} \mathrm{M}^{-1}$ [35]. This is because the adamantyl residue fits perfectly inside the $\beta$-CD cavity. In this present work, we investigated how the affinity between the dimer of adamantane and switchable AZO-CDim 1 may be influenced by the cis/trans ratio of the host molecule. For this purpose, we synthesized the adamantyl dimer EDTA bis-1-aminoadamantyldiamide disodium salt, ADAdim 4, as described by Vasquez Tato et al. [36] (Figure 5). These authors showed that the single interaction between one binding site of the ditopic guest ADAdim 4 and one binding site of a particular $\beta$-CD dimer, bearing a terephthalic acid linker, was independent of the number of binding sites, that is, no cooperative effect was observed and a supramolecular polymer was formed.

ITC is one of the most interesting methods to characterize the interaction of CDs with guests in solution [37,38]. It enables the

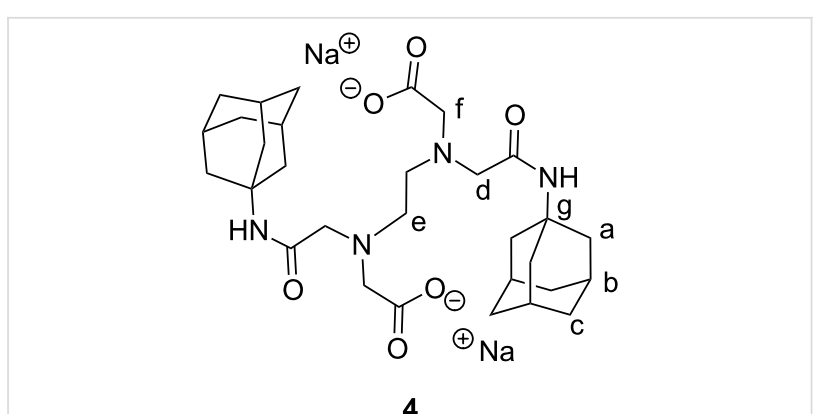

Figure 5: Structure of the ditopic guest ADAdim 4.

enthalpy, entropy and equilibrium constants involved in complexation processes to be determined in a single experiment. Moreover, the guest:host molar ratio (i.e., the stoichiometry of the complex) can be measured. First, enthalpies of dilution of the monotopic hosts $\beta-\mathrm{CD}$ and $\beta-\mathrm{CD}-\mathrm{NH}_{2}$, the ditopic host AZO-CDim 1 and the guest ADAdim 4 were measured in separate experiments to determine the maximum concentration to use for the ITC experiments. Enthalpies of dilution of $\beta-C D$ and $\beta-\mathrm{CD}-\mathrm{NH}_{2}$ were negligible over a broad concentration range, whereas enthalpies of dilution of AZO-CDim 1 were negligible only for concentrations lower than $1 \mathrm{mM}$, which is in agreement with NMR data. As observed by Vásquez Tato and coworkers [39], ADAdim 4 can be considered as a surfactant. However, by using a maximum concentration of $4 \mathrm{mM}$ in the ITC experiment, the effect of any heat resulting from a deaggregation process can be avoided. First, the interactions between $\beta-\mathrm{CD}$ or $\beta-\mathrm{CD}-\mathrm{NH}_{2}$ and ADAdim 4 (added to the CD solution) were studied by ITC. After integrating the heat signal as a function of the molar ratio between the guest and the host, the isotherm was fitted to the one-site binding model as shown in Figure 6 . The average values for the thermodynamic parameters are given in Table 1.

Table 1: Thermodynamic parameters deduced from ITC experiments for the different host-guest systems studied (temperature $298 \mathrm{~K}$ in water).

\begin{tabular}{|c|c|c|c|c|c|c|}
\hline Host & $n^{a}$ & $K_{\mathrm{a}}\left(\mathrm{M}^{-1}\right)$ & $\begin{array}{l}\Delta H^{0} \\
\left(\mathrm{~kJ} \cdot \mathrm{mol}^{-1}\right)\end{array}$ & $\begin{array}{l}\Delta H^{0} \text { guest site } \\
\left(\mathrm{kJ} \cdot \mathrm{mol}^{-1}\right)\end{array}$ & $\begin{array}{l}T \Delta S^{0} \\
\left(\mathrm{~kJ} \cdot \mathrm{mol}^{-1}\right)\end{array}$ & $\Delta G^{0}\left(\mathrm{~kJ} \cdot \mathrm{mol}^{-1}\right)$ \\
\hline$\beta-C D^{b}$ & $0.50(1: 2)$ & $(4.6 \pm 0.2) \cdot 10^{4}$ & $-45.3 \pm 0.3$ & $-22.7 \pm 0.2$ & $-9.3 \pm 0.2$ & $-13.4 \pm 0.1$ \\
\hline$\beta-C D-\mathrm{NH}_{2}{ }^{b}$ & $0.43(1: 2)$ & $(5.0 \pm 0.2) \cdot 10^{4}$ & $-49.0 \pm 0.2$ & $-24.5 \pm 0.1$ & $-11.1 \pm 0.2$ & $-13.4 \pm 0.1$ \\
\hline \multirow[t]{2}{*}{$\begin{array}{l}\text { AZO-CDim } 1^{C} \\
\text { without irradiation }\end{array}$} & $\begin{array}{l}0.13 \\
(0.07: 1)\end{array}$ & $(8 \pm 0.2) \cdot 10^{8}$ & $-95 \pm 0.7$ & $-47.5 \pm 0.4$ & $-17.1 \pm 0.8$ & $-27.7 \pm 0.4$ \\
\hline & $\begin{array}{l}0.77 \\
(0.93: 1)\end{array}$ & $(8 \pm 0.2) \cdot 10^{5}$ & $-67 \pm 0.3$ & $-33.5 \pm 0.2$ & $-13.4 \pm 0.4$ & $-18.4 \pm 0.2$ \\
\hline \multirow[t]{2}{*}{$\begin{array}{l}\text { AZO-CDim } 1^{\mathrm{d}} \\
\text { after irradiation }\end{array}$} & $\begin{array}{l}0.27 \\
(0.37: 1)\end{array}$ & $(8 \pm 0.2) \cdot 10^{8}$ & $-95 \pm 0.8$ & $-47.5 \pm 0.4$ & $-25.2 \pm 0.8$ & $-21.9 \pm 0.4$ \\
\hline & $\begin{array}{l}0.44 \\
(0.63: 1)\end{array}$ & $(8 \pm 0.2) \cdot 10^{5}$ & $-67 \pm 0.4$ & $-33.5 \pm 0.2$ & $-23.8 \pm 2.4$ & $-13.7 \pm 1.2$ \\
\hline
\end{tabular}

$n^{\mathrm{a}}$ : guest:host molar ratio in the complex. The values in parentheses are theoretical values for the formation of complexes with all the binding sites of both guest and host occupied. ' $V$ alues corresponding to the model of one set of sites. 'Values corresponding to the model of two sets of sites. dValues corresponding to the two sets of sites model after irradiation at $365 \mathrm{~nm}$, for $120 \mathrm{~min}$ at $278 \mathrm{~K}$. The units of the experimental enthalpy value are $\mathrm{kJ} \cdot \mathrm{mol}^{-1}$ of the titrating species (i.e. the guest species). 

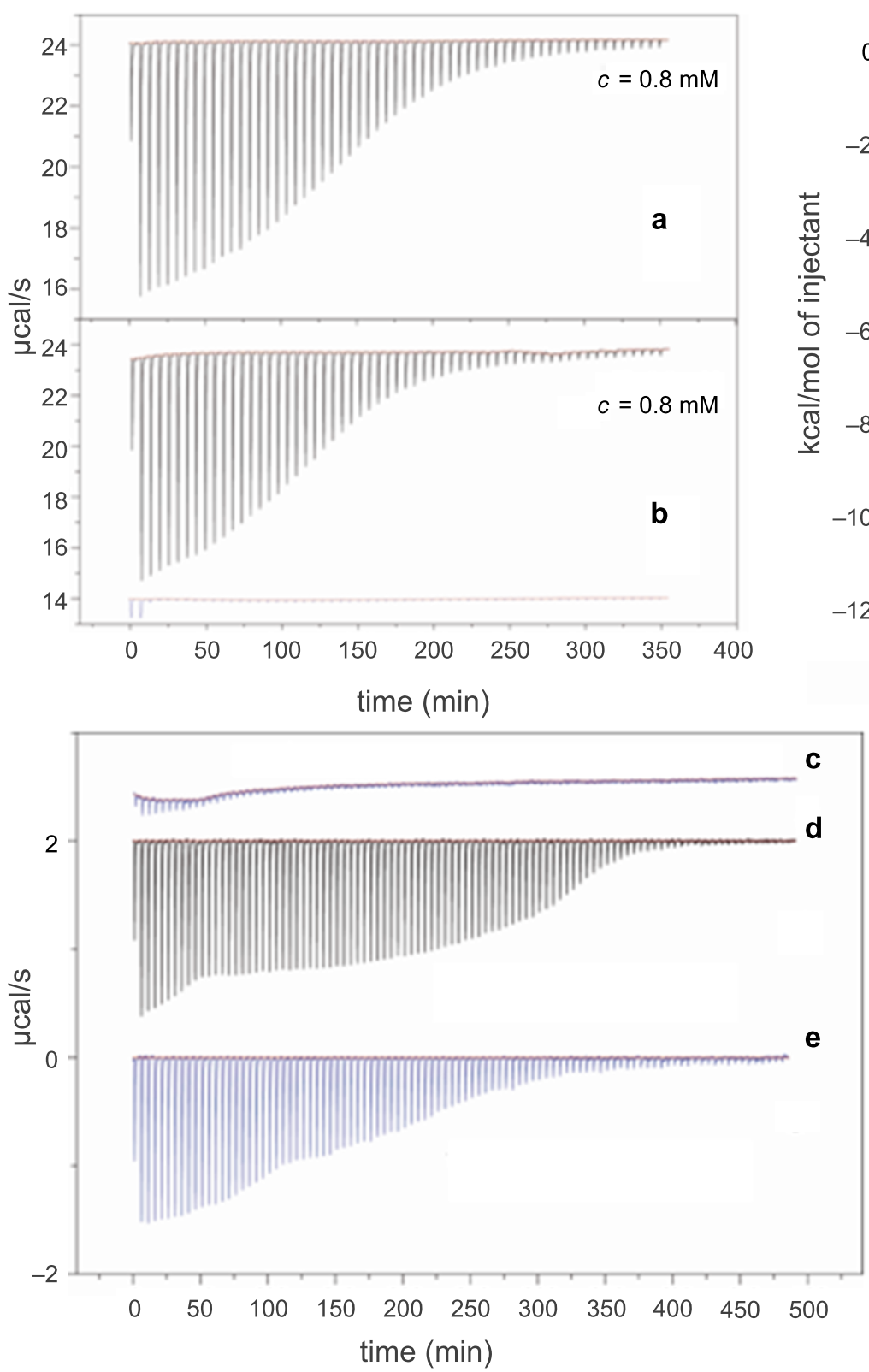
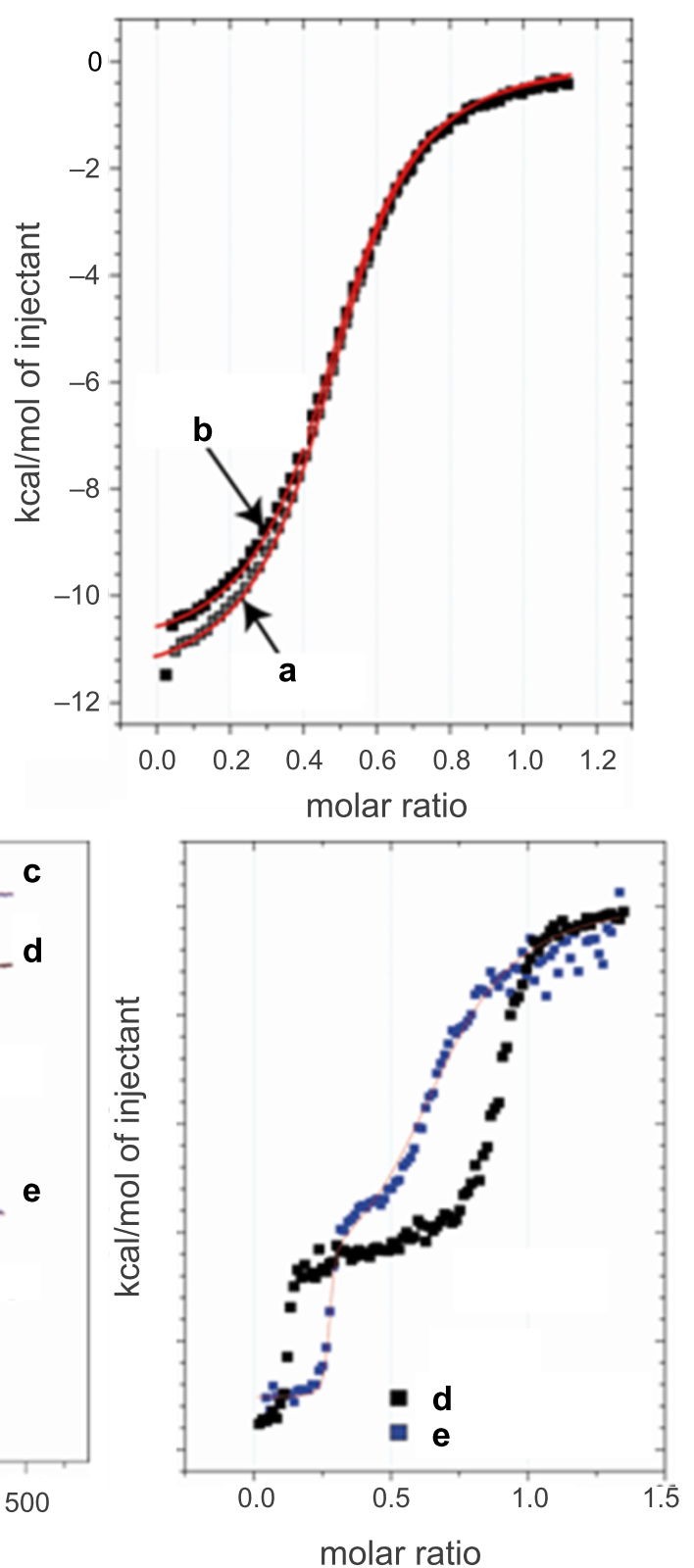

Figure 6: Titration of (a) $\beta-C D(c=0.8 \mathrm{mM})$ and (b) $\beta-C D-\mathrm{NH}_{2}(c=0.8 \mathrm{mM})$ by ADAdim $4(c=4 \mathrm{mM})$. (c) Dilution of ADAdim 4 ( $\left.c=0.6 \mathrm{mM}\right)$ in water at $298 \mathrm{~K}$. Titration of AZO-CDim $1(c=0.1 \mathrm{mM})$ by ADAdim $4(c=0.6 \mathrm{mM})$ (d) before irradiation at $298 \mathrm{~K}$ and (e) after irradiation in water at $365 \mathrm{~nm}$ for $120 \mathrm{~min}$ at $278 \mathrm{~K}$.

For $\beta-\mathrm{CD}$ and $\beta-\mathrm{CD}-\mathrm{NH}_{2}$, the experimental $n$ values $(0.50$ and 0.43 , respectively) for the complexes correspond to one ADAdim 4 for two cyclodextrins (stoichiometry 1:2). Considering the slightly different experimental conditions, all the data obtained are in very good agreement with the literature [36,39]. The same study was performed with AZO-CDim 1 exhibiting a cis/trans ratio of 7:93 and the experimental values are presented in Table 1. As depicted in Figure 6d, two jumps can be observed in the calorimetric titration curves revealing two inde- pendent interactions. The experimental curve was well-fit to the two-sites binding model and the following results were achieved: the first jump corresponds to a very strong interaction between a small fraction of AZO-CDim 1 and ADAdim 4 with $n=0.13$ and $K_{\mathrm{a}}=8 \cdot 10^{8} \mathrm{M}^{-1}$. The second jump corresponds to a weaker interaction between a major fraction of AZO-CDim 1 and ADAdim 4 with $n=0.77$ and $K_{\mathrm{a}}=8 \cdot 10^{5} \mathrm{M}^{-1}$. Assuming a $1: 1$ stoichiometry in both cases, the first jump involves $14 \%$ of the mixture and the second $86 \%$ 
in relatively good agreement with the cis/trans ratio measured by HPLC (7:93). It is therefore tempting to assign the first jump to the complexation between ADAdim 4 and the cis isomer of AZO-CDim 1 and the second jump to the complexation between ADAdim 4 and the trans isomer of AZO-CDim 1.

To confirm this hypothesis, the same ITC study was performed after UV irradiation at $365 \mathrm{~nm}$ for $120 \mathrm{~min}$ (Figure 6e). To improve the stability of cis-AZO-CDim 1, the titration was carried out at $278 \mathrm{~K}$ under the same experimental conditions as previously performed. The average values for the thermodynamic parameters are summarized in Table 1. Again, two jumps can be observed in the enthalpogram (Figure 6d), the stoichiometry of which has been shifted due to the UV irradiation. Neither the $20^{\circ} \mathrm{C}$ difference nor the changing stoichiometry is thought to greatly affect the formation constants of the complexes. We therefore attempted a fit of both experimental curves with the same values for association constants and enthalpies. The following parameter values afforded a reasonable fit: $K_{1}=8 \cdot 10^{8} \mathrm{~L} \cdot \mathrm{mol}^{-1}, \Delta H_{1}=-95 \mathrm{~kJ} \cdot \mathrm{mol}^{-1}$, $K_{2}=8 \cdot 10^{5} \mathrm{~L} \cdot \mathrm{mol}^{-1}, \Delta H_{2}=-67 \mathrm{~kJ} \cdot \mathrm{mol}^{-1}$, with stoichiometries $n_{1}=0.26$ and $n_{2}=0.42$ (vs experimental stoichiometries $n_{1}=0.27$ and $n_{2}=0.44$ ) after irradiation. Assuming a $1: 1$ stoichiometry in both cases, the first jump involves $38 \%$ of the mixture and the second $62 \%$, again matching the cis/trans ratio measured by HPLC (37:63). This unambiguously proves that the two jumps detected by ITC correspond to the complexation of both isomers of AZO-CDim $\mathbf{1}$.

Interestingly, the association constants measured for the ditopic host (about $10^{9} \mathrm{M}^{-1}$ for the cis isomer and $10^{6} \mathrm{M}^{-1}$ for the trans isomer) are orders of magnitude larger than the association constant for the monotopic $\beta-\mathrm{CD}\left(K_{\mathrm{a}}=5 \cdot 10^{4} \mathrm{M}^{-1}\right)$. This means that the complexation is highly cooperative, particularly in the case of the cis isomer. Although it was not demonstrated, such an additional interaction could explain why the association constant between the trans isomer of the ditopic host AZO-CDim 1 and the ditopic guest ADAdim 4 is significantly larger than that between $\beta-C D$ and ADAdim 4. This, in turn, hints at particularly well matched conformations, as shown by the molecular simulation (see below).

The ${ }^{1} \mathrm{H}$ NMR spectra of AZO-CDim 1 with a cis/trans ratio of 7:93 were obtained in the absence or presence of an equimolar concentration of ADAdim 4 (Figure 7a). As previously stated, each cis and trans isomer could not be isolated in pure form, complicating the NMR study. In the presence of the ditopic guest ADAdim 4, a strong broadening of all signals was observed, indicating the presence of large objects in solution. A ROESY experiment was also carried out and although the presence of cross-correlation peaks between protons of AZO-
CDim 1 and ADAdim 4 supports an inclusion complex, the strong signal broadening impeded any assignment (data not shown).

Diffusion-ordered spectroscopy (DOSY) is a solution-based NMR method used to discriminate signals arising from different species by their diffusion rates. This method is very helpful and convenient for characterizing molecular aggregates or inclusion complexes [40]. The diffusion coefficient $(D)$ is directly related to the molecular mass of the observed species in solution. In other words, when the molecular mass increases, the diffusion rate decreases. The DOSY spectra for ADAdim 4, AZOCDim 1, and an equimolecular mixture of both were recorded in $\mathrm{D}_{2} \mathrm{O}$ (Figure $7 \mathrm{~b}$ ) and the measured $D$ values were $3.540 \cdot 10^{-10} \mathrm{~m}^{2} \cdot \mathrm{s}^{-1}, 2.293 \cdot 10^{-10} \mathrm{~m}^{2} \cdot \mathrm{s}^{-1}$ and $1.33 \cdot 10^{-10} \mathrm{~m}^{2} \cdot \mathrm{s}^{-1}$, respectively. The $D$ value of ADAdim 4 is smaller than that of AZO-CDim 1, in accordance with their molecular masses. It is usually assumed that the $D$ value of an inclusion complex is the same as that of the host molecule alone [40], however, this was not observed in our case, which is in agreement with the formation of larger objects in solution.

The experimental data strongly suggests that AZO-CDim $\mathbf{1}$ is a switchable host which forms two different inclusion complexes with this ditopic guest. The structural analyses of the molecular dynamics trajectories of the two configurations of the AZOCDim 1 systems enable us to draw some conclusions as to how the adamantyl units could be contained in one or both cavities. To further support our assumptions, the corresponding systems were built and minimized. The following main conclusions can be drawn. For the first, in the cis configuration, both cavities of the ditopic host AZO-CDim 1 are available for complexation and their orientation favors the simultaneous inclusion of both adamantyl units of ADAdim 4, forming a 1:1 chelate-type complex depicted in Figure 8a. The chelate effect has been extensively studied by Breslow et al. [41,42] among others and a higher stability constant is expected due to the strong cooperative effect. Regarding the second main conclusion, the size and rigidity of the linker in AZO-CDim 1 prevent the trans configuration from forming ditopic 1:1 complexes upon complexation with only one molecule of ADAdim 4. Nevertheless, the two cavities remain available for complex formation through their wider rim with two adamantyl units belonging to two different ADAdim 4 molecules, leading to the formation of supramolecular polymers with an $n: n$ stoichiometry. This situation has already been encountered in the complex of ADAdim 4 and a $\beta$-CD dimer bearing a terephthalic moiety as the linker [36]. At this stage, based on the molecular dynamics study, at least two supramolecular polymers can be considered: the first is linear, as often described in the literature $[43,44]$ (Figure $8 b$ ), and the second is cyclic (Figure 8c). Furthermore, it is possible 


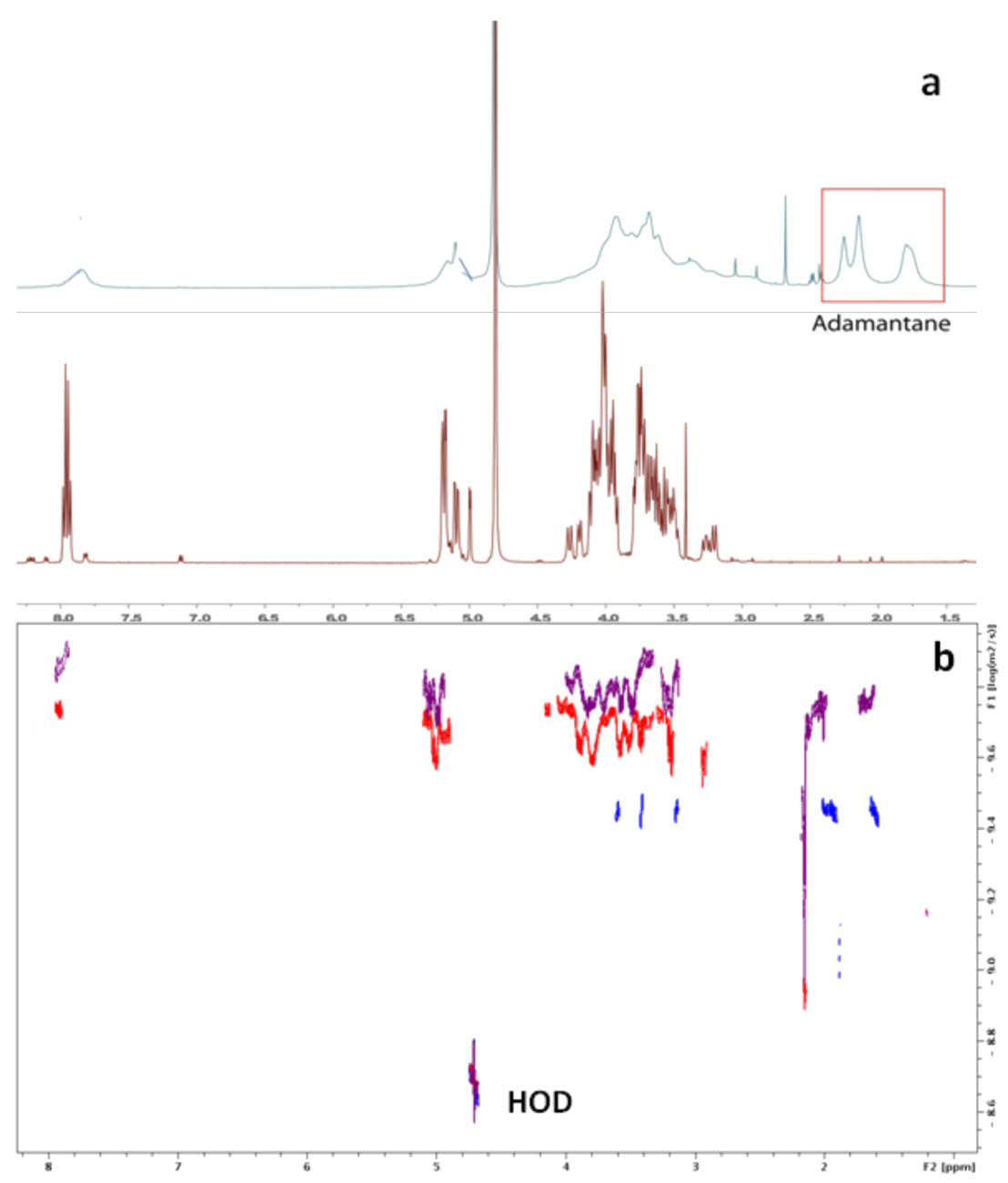

Figure 7: (a) ${ }^{1} \mathrm{H}$ NMR spectra of AZO-CDim $1\left(500 \mathrm{MHz}, \mathrm{D}_{2} \mathrm{O}, 2.5 \mathrm{mM}\right)$ in the absence (bottom) and presence of ADAdim 4 (2.5 mM, top); (b) DOSY spectra of AZO-CDim 1 (red), ADAdim 4 (blue) and an equimolecular mixture of both (purple), (1 mM, $D_{2} \mathrm{O}$ ).

that such linear or cyclic polymers are aggregated into larger objects stabilized by hydrogen bonds between cyclodextrin moieties and by $\pi$-stacking interactions between azobenzene linkers.

Finally, according to the computational data, the complexes of AZO-CDim 1 with ADAdim 4 are further stabilized by intramolecular interactions between $\mathrm{CD}$ subunits that are more favorable in the cis than in the trans configurational arrangement, which is in agreement with the ITC data.

\section{Experimental \\ Materials and methods}

All solvents were used as purchased, unless otherwise noted. All starting materials were used without purification. $\beta-\mathrm{CD}$ was purchased from Roquette Frères (Lestrem, France) and $\beta$-CD$\mathrm{NH}_{2}$ was synthesized as previously described [31] or purchased from Biocydex (Poitiers, France). Analytical TLC was performed using Silica Gel $60 \mathrm{~F}_{254}$ plates (Merck, Germany). Eluents were mixtures of dichloromethane/methanol or cyclohexane/ethyl acetate. Ratios are specified in each case in the experimental section. Products were illuminated under UV light $(\lambda=254 \mathrm{~nm})$ followed by charring with vanillin $/ \mathrm{H}_{2} \mathrm{SO}_{4}$.

UV analyses were performed on a UV-vis Cary VARIAN spectrophotometer coupled with an optic fiber. A 6 Watt mercury lamp was used $(\lambda=365 \mathrm{~nm})$ for the irradiation of aqueous AZO-CDim 1 solutions $\left(c=10^{-4} \mathrm{M}\right)$.

Stepwise control of the reactions was readily achieved by ESIMS in the positive ion mode using a ZQ 4000 quadrupole mass spectrometer (Waters-Micromass, Manchester, UK). High resolution electrospray mass spectra (HRMS-ESI) operated in the positive ion mode were obtained on a Q-TOF Ultima Global 


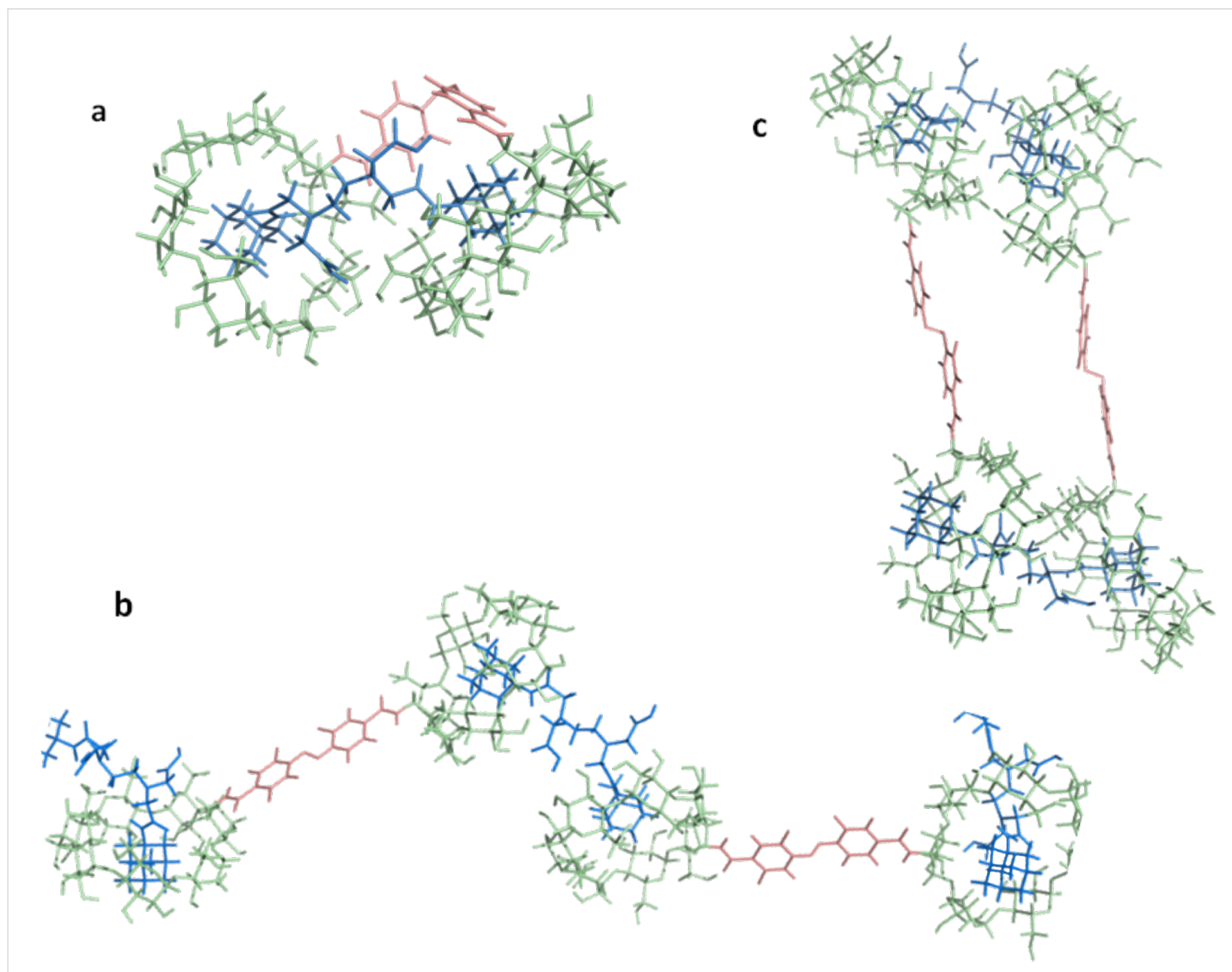

Figure 8: Proposed structures of inclusion complexes with the ditopic host AZO-CDim 1 and the ditopic guest ADAdim 4 after minimization by molecular modeling methods: (a) 1:1 chelate-type complex with AZO-CDim 1 in its cis configuration; linear (b) and cyclic (c) supramolecular polymers with AZO-CDim 1 in its trans configuration.

instrument (Waters-Micromass, Manchester, UK). Data acquisition and processing were performed with MassLynx 4.0 software. High resolution mass spectra were recorded in the positive mode on a ZabSpec TOF (Micromass, UK) tandem hybrid mass spectrometer with EBETOF geometry. The compounds were individually dissolved in a $1: 1$ water $/ \mathrm{CH}_{3} \mathrm{CN}$ mixture at a concentration of $10 \mu \mathrm{g} \cdot \mathrm{cm}^{-3}$ and then infused into the electrospray ion source at a flow rate of $10 \mathrm{~mm} \cdot \mathrm{min}^{-1}$ at $333 \mathrm{~K}$. The mass spectrometer was operated at $4 \mathrm{kV}$ while scanning the magnet over a typical range of 4000-100 Da. The mass spectra were collected as a continuum profile data. Accurate mass measurement was achieved using polyethylene glycol as the internal reference mass with a resolving power set to a minimum of 10,000 (10\% valley).

NMR experiments were performed at 300.13 and $600.13 \mathrm{MHz}$ using Bruker AVANCE DPX300 and AVANCE 600 spectrometers equipped with a Z-gradient unit for pulsed-field gradient spectroscopy. $\mathrm{Me}_{4} \mathrm{Si}$ was used as an external standard and calibration was performed using the signal of the residual protons or of the carbon of the solvents as a secondary reference. Measurements were performed at $300 \mathrm{~K}$ with careful temperature regulation. The length of the $90^{\circ}$ pulse was approximately $7 \mu \mathrm{s}$. 1D NMR data spectra were collected using $16 \mathrm{~K}$ data points. $2 \mathrm{D}$ experiments were run using $1 \mathrm{~K}$ data points and 512 time increments. The phase-sensitive (TTPI) sequence was used and processing resulted in a $1 \mathrm{~K} \cdot 1 \mathrm{~K}$ (real-real) matrix. The DOSY experiments were performed using the ledbpgp $2 \mathrm{~s}$ sequence from the Bruker library, with stimulated echo, longitudinal eddy current compensation, bipolar gradient pulses and two spoil gradients using 16 different gradient values varying from 2 to $95 \%$ of the maximum gradient strength. A $100 \mathrm{~ms}$ diffusion time and a $2.2 \mathrm{~ms}$ gradient length were used.

Isothermal Titration Calorimetry (ITC) was performed using a VP-ITC microcalorimeter at $298 \mathrm{~K}$ or $278 \mathrm{~K}$ in pure water. 
Briefly, titration was carried out with 60 injections of $5 \mu \mathrm{L}$ every $6 \mathrm{~min}$. Control experiments were performed by the dilution of the guest solution in water and showed small heats of dilution. Thus, these results were subtracted from each titration to remove guest heats of dilution. The experimental data were fitted to a theoretical titration curve using Origin 7.0, Microcal software with the one set or two sets of sites models. During this fitting, enthalpy $(\Delta H)$, stoichiometry $(n)$ and association constants $\left(K_{\mathrm{a}}\right)$ were adjustable parameters.

\section{Molecular modeling}

Initial geometries of the $\beta$-cyclodextrin dimers studied in this work were built using the LEaP program from the AmberTools 1.4 distribution, following the strategy and methodology previously established [45]. Except for the linker, the CD fragments were taken from the R.E.DD.B. database [46] under project F-85 (http://q4md-forcefieldtools.org/REDDB/). Both the linker fragment and the cation were defined and parameterized according to the strategy previously developed using the RED program [47] along with the RED server [48].

Molecular dynamics (MD) simulations were performed using the SANDER module of the AMBER10 program suite to perform MD simulations on the aforementioned complexes [49]. The systems were solvated in a truncated octahedral box with a buffer distance of $10.0 \AA$. The q $4 \mathrm{md}-\mathrm{CD}$ force field parameters were used to model the $\beta$-CD systems [45]. The parameters used for water were taken from the TIP3P model [50]. Classic MD simulations of $50 \mathrm{~ns}$ were then performed using the NPT ensemble at a pressure of $1 \mathrm{~atm}$ and a temperature of $300 \mathrm{~K}$. In order to obtain representative ensembles of conformations for the two bis-CD systems, molecular configurations from MD trajectories were clustered.

$\mathrm{Ab}$ initio calculations were performed with the Gaussian 09 program [50] to perform quantum chemical calculations. The structures corresponding to the two configurations of the linker were optimized at the B3LYP level of theory using the $6-31+\mathrm{G}^{*}$ basis set.

\section{Synthesis}

4,4'-Dicarboxyazobenzene (2): $p$-nitrobenzoic acid (7.72 g, $46.2 \mathrm{mmol}, 1$ equiv) and sodium hydroxide (14.24 g, $356 \mathrm{mmol}$, 7.8 equiv) in $100 \mathrm{~mL}$ of water were heated at $338 \mathrm{~K}$ for $1 \mathrm{~h}$. Then, $120 \mathrm{~mL}$ of $60 \mathrm{wt} \%$ glucose solution in water was added dropwise in two portions separated by $1 \mathrm{~h}$ of stirring. The mixture was heated at $353 \mathrm{~K}$ for $3 \mathrm{~h}$ and dropped into a large crystallizer where a precipitate appeared on the surface after several hours. The solid was filtered, dissolved in hot water, acidified with $100 \mathrm{~mL}$ of acetic acid, the precipitate filtered again and dried under reduced pressure. 4,4'-Dicarboxyazobenzene (2) was obtained as a pink solid ( $m=6.11 \mathrm{~g}$ ) with a yield of $49 \%$. The analyses are in full agreement with the literature [30]. Mp > $523 \mathrm{~K}(\mathrm{dec}) ;{ }^{1} \mathrm{H}$ NMR (DMSO- $\left.d_{6}, 300.13 \mathrm{MHz}\right) \delta 8.16(\mathrm{~d}, J=$ $8.4 \mathrm{~Hz}, 4 \mathrm{H}), 8.01(\mathrm{~d}, J=8.4 \mathrm{~Hz}, 4 \mathrm{H}) \mathrm{ppm} ;{ }^{13} \mathrm{C}$ NMR (DMSO$\left.d_{6}, 75.77 \mathrm{MHz}\right) \delta 166.9,154.3,133.7,130.9,123.0 \mathrm{ppm} ;$ ESIMS $(\mathrm{m} / \mathrm{z})$ : $[\mathrm{M}-\mathrm{H}]^{-}$calcd for $\mathrm{C}_{14} \mathrm{H}_{9} \mathrm{~N}_{2} \mathrm{O}_{4}, 269.1$; found, 268.9 .

4,4'-Dicarboxyazobenzene bis( $N$-hydroxysuccinimide ester) (3): Compound 2 (1.0 g, $3.70 \mathrm{mmol}, 1$ equiv), $N$-hydroxysuccinimide (1.87 g, $16.28 \mathrm{mmol}, 4.4$ equiv) and DMAP (90 mg, $0.74 \mathrm{mmol}, 0.2$ equiv) were dissolved in $10 \mathrm{~mL}$ of DMF at room temperature. After $10 \mathrm{~min}$ of stirring, EDCI (2.13 g, $11.1 \mathrm{mmol}, 3$ equiv) was added, then the solution was stirred at room temperature for $16 \mathrm{~h}$ under an inert atmosphere. The mixture was extracted by $100 \mathrm{~mL}$ of DCM and $100 \mathrm{~mL}$ of $\mathrm{HCl}$ $(0.1 \mathrm{M})$. The aqueous phase was extracted twice with $50 \mathrm{~mL}$ of DCM. Organic phases were combined, dried over $\mathrm{Na}_{2} \mathrm{SO}_{4}$ and purified over a plug-in of silica with DCM/MeOH $(99: 1 \mathrm{v} / \mathrm{v})$ as eluent to obtain 3 as a red solid ( $m=1.41 \mathrm{~g})$ with a yield of $83 \% . \mathrm{Mp}>523 \mathrm{~K}(\mathrm{dec}) ;{ }^{1} \mathrm{H} \mathrm{NMR}\left(\mathrm{CDCl}_{3}, 300.13 \mathrm{MHz}\right) \delta 8.33$ $(\mathrm{d}, J=8.4 \mathrm{~Hz}, 4 \mathrm{H}), 8.07$ (d, $J=8.4 \mathrm{~Hz}, 4 \mathrm{H}), 2.95(\mathrm{~s}, 8 \mathrm{H}) \mathrm{ppm}$; ${ }^{13} \mathrm{C} \mathrm{NMR}\left(\mathrm{CDCl}_{3}, 75.77 \mathrm{MHz}\right) \delta 169.3,161.4,155.9,132.0$, 127.7, 123.6, 25.9 ppm; HRMS-ESI $(\mathrm{m} / \mathrm{z}):[\mathrm{M}+\mathrm{Na}]^{+}$calcd for $\mathrm{C}_{22} \mathrm{H}_{16} \mathrm{~N}_{4} \mathrm{O}_{8} \mathrm{Na}$, 487.0866; found, 487.0876.

$N, N^{\prime}$-Bis $\left[6^{\mathrm{I}}\right.$-deoxy- $\beta$-cyclodextrin- $6^{\mathrm{I}}$-yl $]$ carboxamide-4,4' azobenzene, AZO-CDim (1): $\beta-\mathrm{CD}-\mathrm{NH}_{2}(2.02 \mathrm{~g}, 1.78 \mathrm{mmol}$, 2 equiv) and 3 (404 $\mathrm{mg}, 0.87 \mathrm{mmol}, 1$ equiv) were dissolved in $5 \mathrm{~mL}$ of dried distilled DMF. After $16 \mathrm{~h}$ of stirring at room temperature, the mixture was concentrated and the product precipitated by addition of acetone, then dried under reduced pressure. The product 1 was obtained as an orange powder ( $m=4.44 \mathrm{~g}$ ) with a quantitative yield and an HPLC purity over $98 \%$. Then, the product was purified by flash chromatography (20 min, $\mathrm{H}_{2} \mathrm{O} / \mathrm{MeOH}$ from 90:10 to 10:90 (v/v), $40 \mathrm{~mL} \cdot \mathrm{min}^{-1}$ ) to afford compound 1 (2.75 g, 62\%). Mp $423 \mathrm{~K}$ (dec); ${ }^{1} \mathrm{H}$ NMR $\left(\mathrm{D}_{2} \mathrm{O}, 600.13 \mathrm{MHz}\right) \delta 7.94\left(\mathrm{~d},{ }^{3} J_{\mathrm{H} 10-\mathrm{H} 11}=8.1 \mathrm{~Hz}, \mathrm{H}_{10}, 4 \mathrm{H}\right)$, $7.90\left(\mathrm{~d},{ }^{3} \mathrm{~J}_{\mathrm{H} 11-\mathrm{H} 10}=8.1 \mathrm{~Hz}, \mathrm{H}_{11}, 4 \mathrm{H}\right), 4.97-5.17\left(\mathrm{~m}, \mathrm{H}_{1}{ }^{\mathrm{I}-\mathrm{VII}}\right.$, $14 \mathrm{H}), 3.14-4.25\left(\mathrm{~m}, \mathrm{H}_{2}{ }^{\mathrm{I}-\mathrm{VII}-} \mathrm{H}_{3}{ }^{\mathrm{I}-\mathrm{VII}-} \mathrm{H}_{4}{ }^{\mathrm{I}-\mathrm{VII}-} \mathrm{H}_{5}{ }^{\mathrm{I}-\mathrm{VII}}-\right.$

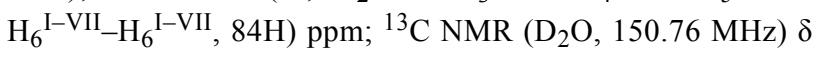
$168.19(\mathrm{C}=\mathrm{O}), 153.56\left(\mathrm{C}_{12}\right), 135.35\left(\mathrm{C}_{9}\right), 128.21\left(\mathrm{C}_{10}\right), 122.94$ $\left(\mathrm{C}_{11}\right), 101.28-101.93\left(\mathrm{C}_{1}{ }^{\mathrm{I}-\mathrm{VII}}\right), 83.69\left(\mathrm{C}_{4}{ }^{\mathrm{I}}\right), 80.26-81.05$ $\left(\mathrm{C}_{4}{ }^{\mathrm{II}-\mathrm{VII}}\right), 71.63-73.54\left(\mathrm{C}_{2}{ }^{\mathrm{I}-\mathrm{VII}}-\mathrm{C}_{3}{ }^{\mathrm{I}-\mathrm{VII}}-\mathrm{C}_{5}{ }^{\mathrm{II}-\mathrm{VII}}\right), 70.44\left(\mathrm{C}_{5}{ }^{\mathrm{I}}\right)$, 59.16-60.42 $\left(\mathrm{C}_{6}{ }^{\mathrm{II}-\mathrm{VII}}\right), 41.15\left(\mathrm{C}_{6}{ }^{\mathrm{I}}\right)$; HRMS-ESI $(\mathrm{m} / \mathrm{z})$ : [M + $\mathrm{Na}]^{+}$calcd for $\mathrm{C}_{98} \mathrm{H}_{148} \mathrm{~N}_{4} \mathrm{O}_{70} \mathrm{Na}, 2523.8042$; found, 2523.8125 .

EDTA bis-1-adamantanylamine disodium salt, ADAdim (4): Adamantine (1.01 g, $6.68 \mathrm{mmol}, 2.1$ equiv) was dissolved in $30 \mathrm{~mL}$ of dried DMF and $10 \mathrm{~mL}$ of $\mathrm{Et}_{3} \mathrm{~N}$. The mixture was 
cooled to $273 \mathrm{~K}$ under an inert atmosphere and EDTA anhydride (0.82 g, $3.20 \mathrm{mmol}, 1$ equiv) was added portionwise. After $16 \mathrm{~h}$ of stirring under inert atmosphere, the solvent was removed under vacuum, and $10 \mathrm{~mL}$ of water was added and the solution was neutralized by $\mathrm{HCl}$. The precipitate was washed with water, dried under reduced pressure then recrystallized in $\mathrm{MeOH}$ to obtain the diacidic compound. The diacid $(814 \mathrm{mg}$, $1.46 \mathrm{mmol}, 1$ equiv) was suspended in water $(10 \mathrm{~mL})$ and $\mathrm{NaOH}$ (116 mg, $2.90 \mathrm{mmol}, 2$ equiv) was added. The mixture was sonicated for $10 \mathrm{~min}$ and the product precipitated by addition of $100 \mathrm{~mL}$ of acetone. The solid was filtered, washed with acetone and dried under reduced pressure to obtain ADAdim 4 as a white powder $(m=420 \mathrm{mg})$, with a yield of $52 \%$ over the two steps. The analyses are in full agreement with the literature [36]. Mp 505-506 K; ${ }^{1} \mathrm{H}$ NMR (DMSO- $\left.d_{6}, 300.13 \mathrm{MHz}\right) \delta 7.47$ $(\mathrm{NH}, 2 \mathrm{H}), 3.37\left(\mathrm{H}_{\mathrm{f}}, 4 \mathrm{H}\right), 3.15\left(\mathrm{H}_{\mathrm{d}}, 4 \mathrm{H}\right), 2.72\left(\mathrm{H}_{\mathrm{e}}, 4 \mathrm{H}\right), 1.99$ $\left(\mathrm{H}_{\mathrm{b}}, 6 \mathrm{H}\right), 1.91\left(\mathrm{H}_{\mathrm{a}}, 12 \mathrm{H}\right), 1.60\left(\mathrm{H}_{\mathrm{c}}, 12 \mathrm{H}\right) ;{ }^{13} \mathrm{C}$ NMR (DMSO$\left.d_{6}, 75.77 \mathrm{MHz}\right) \delta 172.5,169.3,58.8,55.9,52.4,50.8,41.1$, $36.1,29.0$; HRMS-ESI $(\mathrm{m} / \mathrm{z}):[\mathrm{M}+\mathrm{Na}]^{+}$calcd for $\mathrm{C}_{30} \mathrm{H}_{46} \mathrm{~N}_{4} \mathrm{O}_{6} \mathrm{Na}$, 581.3315; found, 581.3299.

\section{Acknowledgements}

The authors would like to acknowledge financial support from the Agence Nationale de la Recherche ANR, France (CP2D program, CYCLOCAT project). Mathilde Bellot and Dr David Mathiron are thanked for their help with ITC and NMR experiments, respectively.

\section{References}

1. Hedges, A. R. Chem. Rev. 1998, 98, 2035-2044. doi:10.1021/cr970014w

2. Dodziuk, H. Cyclodextrins and their complexes; Wiley-VCH: Weinheim, Germany, 2006. doi:10.1002/3527608982

3. Bilensoy, E., Ed. Cyclodextrins in Pharmaceutics, Cosmetics and Biomedicine; John Wiley \& Sons, Inc.: Hoboken, USA, 2011. doi:10.1002/9780470926819

4. Hirayama, F.; Uekama, K. Adv. Drug Delivery Rev. 1999, 36, 125-141. doi:10.1016/S0169-409X(98)00058-1

5. Uekama, K.; Hirayama, F.; Irie, T. Chem. Rev. 1998, 98, 2045-2076. doi:10.1021/cr970025p

6. Loftsson, T.; Brewster, M. E. J. Pharm. Pharmacol. 2010, 62, 1607-1621. doi:10.1111/j.2042-7158.2010.01030.x

7. Hicks, K. B.; Haines, R. M.; Tong, C. B. S.; Sapers, G. M.; El-Atawy, Y.; Irwin, P. L.; Seib, P. A. J. Agric. Food Chem. 1996, 44, 2591-2594. doi:10.1021/jf960181h

8. Shaw, P. E.; Wilson, C. W. J. Food Sci. 1983, 48, 646-647. doi:10.1111/j.1365-2621.1983.tb10811.x

9. Liu, Y.; Chen, Y. Acc. Chem. Res. 2006, 39, 681-691. doi:10.1021/ar0502275

10. Harada, T.; Pham, D.-T.; Leung, M. H. M.; Ngo, H. T.; Lincoln, S. F.; Easton, C. J.; Kee, T. W. J. Phys. Chem. B 2011, 115, 1268-1274. doi:10.1021/jp1096025

11. Liu, Y.; Chen, Y.; Liu, S.-X.; Guan, X.-D.; Wada, T.; Inoue, Y. Org. Lett. 2001, 3, 1657-1660. doi:10.1021/ol015820a
12. Wilson, D.; Perlson, L.; Breslow, R. Bioorg. Med. Chem. 2003, 11, 2649-2653. doi:10.1016/S0968-0896(03)00153-6

13. Fujita, K.; Ejima, S.; Imoto, T. J. Chem. Soc., Chem. Commun. 1984, 1277-1278. doi:10.1039/c39840001277

14. Sikorski, C. T.; Petter, R. C. Tetrahedron Lett. 1994, 35, 4275-4278. doi:10.1016/S0040-4039(00)73332-6

15. Breslow, R.; Zhang, B. J. Am. Chem. Soc. 1996, 118, 8495-8496. doi:10.1021/ja961567b

16. Edwards, W. B.; Reichert, D. E.; d'Avignon, D. A.; Welch, M. J. Chem. Commun. 2001, 1312-1313. doi:10.1039/B102814F

17. Charbonnier, F.; Marsura, A.; Pintér, I. Tetrahedron Lett. 1999, 40, 6581-6583. doi:10.1016/S0040-4039(99)01313-1

18. Porwanski, S.; Kryczka, B.; Marsura, A. Tetrahedron Lett. 2002, 43, 8441-8443. doi:10.1016/S0040-4039(02)02101-9

19. Cieslinski, M. M.; Clements, P.; May, B. L.; Easton, C. J.; Lincoln, S. F. J. Chem. Soc., Perkin Trans. 2 2002, 947-952. doi:10.1039/b200026c

20. Mourer, M.; Hapiot, F.; Monflier, E.; Menuel, S. Tetrahedron 2008, 64, 7159-7163. doi:10.1016/j.tet.2008.05.095

21. Hamon, F.; Djedaini-Pilard, F.; Barbot, F.; Len, C. Tetrahedron 2009, 65, 10105-10123. doi:10.1016/j.tet.2009.08.063

22. Merino, E.; Ribagorda, M. Beilstein J. Org. Chem. 2012, 8, 1071-1090. doi:10.3762/bjoc.8.119

23. Dugave, C.; Demange, L. Chem. Rev. 2003, 103, 2475-2532. doi:10.1021/cr0104375

24. Takashima, Y.; Nakayama, T.; Miyauchi, M.; Kawaguchi, Y.; Yamaguchi, H.; Harada, A. Chem. Lett. 2004, 33, 890-891. doi:10.1246/cl.2004.890

25. Qu, D.-H.; Wang, G.-C.; Ren, J.; Tian, H. Org. Lett. 2004, 6, 2085-2088. doi:10.1021/ol049605g

26. Blaszkiewicz, C.; Bricout, H.; Léonard, E.; Len, C.; Landy, D.; Cézard, C.; Djedaïni-Pilard, F.; Monflier, E.; Tilloy, S. Chem. Commun. 2013, 49, 6989-6991. doi:10.1039/c3cc43647k

27. Liu, Y.; Kang, S.; Chen, Y.; Yang, Y.-W.; Huskens, J. J. Inclusion Phenom. Macrocyclic Chem. 2006, 56, 197-201. doi:10.1007/s10847-006-9083-4

28. Aoyagi, T.; Ueno, A.; Fukushima, M.; Osa, T. Macromol. Rapid Commun. 1998, 19, 103-105 doi:10.1002/(SICI)1521-3927(19980201)19:2<103::AID-MARC103>3.0 .CO;2-R

29. Casas-Solvas, J. M.; Maros-Maldonado, M. C.; Vargas-Berenguel, A. Tetrahedron 2008, 64, 10919-10923. doi:10.1016/j.tet.2008.08.098

30. Mukherjee, P. S.; Das, N.; Kryschenko, Y. K.; Arif, A. M.; Stang, P. J. J. Am. Chem. Soc. 2004, 126, 2464-2473. doi:10.1021/ja039235b

31. Angelova, A.; Fajolles, C.; Hocquelet, C.; Djedaïni-Pilard, F.; Lesieur, S.; Bonnet, V.; Perly, B.; Lebas, G.; Mauclaire, L. J. Colloid Interface Sci. 2008, 322, 304-314. doi:10.1016/j.jcis.2008.03.023 And references therein.

32. Basheer, M. C.; Oka, Y.; Mathews, M.; Tamaoki, N. Chem. - Eur. J. 2010, 16, 3489-3496. doi:10.1002/chem.200902123

33. Koshima, H.; Ojima, N.; Uchimoto, H. J. Am. Chem. Soc. 2009, 131, 6890-6891. doi:10.1021/ja8098596

34. Raul, H. In Photochemistry and Photophysics; Rabek, J. F., Ed.; CRC Press: Boca Raton, FL, USA, 1990.

35. Kauscher, U.; Ravoo, B. J. Beilstein J. Org. Chem. 2012, 8, 1543-1551. doi:10.3762/bjoc.8.175

36. Soto Tellini, V. H.; Jover, A.; Garcia, J. C.; Galantini, L.; Meijide, F.; Vasquez Tato, J. J. Am. Chem. Soc. 2006, 128, 5728-5734. doi:10.1021/ja0572809 
37. Bouchemal, K.; Mazzafero, S. Drug Discovery Today 2012, 17, 623-629. doi:10.1016/j.drudis.2012.01.023

And references therein.

38. Hamon, F.; Violeau, B.; Turpin, F.; Bellot, M.; Bouteiller, L.; Djedaïni-Pilard, F.; Len, C. Synlett 2009, 2875-2879. doi:10.1055/s-0029-1217988

39. Carrazana, J.; Jover, A.; Meijide, F.; Soto, V. H.; Vázquez Tato, J. J. Phys. Chem. B 2005, 109, 9719-9726. doi:10.1021/jp0505781

40. Xu, J.; Tan, T.; Kenne, L.; Sandström, C. New J. Chem. 2009, 33, 1057-1063. doi:10.1039/b900164f

41. Breslow, R. Supramol. Chem. 1993, 1, 111-118. doi:10.1080/10610279308040656

42. Zhang, B.; Breslow, R. J. Am. Chem. Soc. 1993, 115, 9353-9354. doi:10.1021/ja00073a087

43. Yang, Y.; Zhang, Y.-M.; Chen, Y.; Zhao, D.; Chen, J.-T.; Liu, Y. Chem. - Eur. J. 2012, 18, 4208-4215. doi:10.1002/chem.201103445

44. Takashima, Y.; Osaki, M.; Ishimaru, Y.; Yamaguchi, H.; Harada, A. Angew. Chem., Int. Ed. 2011, 50, 7524-7528. doi:10.1002/anie.201102834 And references therein.

45. Cézard, C.; Trivelli, X.; Aubry, F.; Djedaïni-Pilard, F.; Dupradeau, F.-Y. Phys. Chem. Chem. Phys. 2011, 13, 15103-15121. doi:10.1039/c1cp20854c

46. Dupradeau, F.-Y.; Cézard, C.; Lelong, R.; Stanislawiak, E.; Pêcher, J.; Delepine, J. C.; Cieplak, P. Nucleic Acids Res. 2008, , D360-D367. doi:10.1093/nar/gkm887

47. Dupradeau, F.-Y.; Pigache, A.; Zaffran, T.; Savineau, C.; Lelong, R.; Grivel, N.; Lelong, D.; Rosanski, D.; Cieplak, P. Phys. Chem. Chem. Phys. 2010, 12, 7821-7839. doi:10.1039/c0cp00111b

48. Vanquelef, E.; Simon, S.; Marquant, G.; Garcia, E.; Klimerak, G.; Delepine, J. C.; Cieplak, P.; Dupradeau, F.-Y. Nucleic Acids Res. 2011, 39 (Suppl. 2), W511-W517. doi:10.1093/nar/gkr288

49. AMBER, Version 10; University of California: San Francisco, USA, 2008.

50. Jorgensen, W. L.; Chandrasekhar, J.; Madura, J. D.; Impey, R. W.; Klein, M. L. J. Chem. Phys. 1983, 79, 926-935. doi:10.1063/1.445869

\section{License and Terms}

This is an Open Access article under the terms of the Creative Commons Attribution License (http://creativecommons.org/licenses/by/2.0), which permits unrestricted use, distribution, and reproduction in any medium, provided the original work is properly cited.

The license is subject to the Beilstein Journal of Organic Chemistry terms and conditions: (http://www.beilstein-journals.org/bjoc)

The definitive version of this article is the electronic one which can be found at: doi:10.3762/bjoc. 10.304 